\title{
As palavras cruzadas como fenômeno da linguagem: o auxílio do dicionário
}

Félix Bugueño Miranda

Universidade Federal do Rio Grande do Sul

felixv@uol.com.br

\section{Resumo}

As palavras cruzadas são um passatempo muito comum. Raramente, no entanto, é feita uma reflexão sobre os fenômenos da linguagem que elas espelham. O objetivo do presente artigo é refletir sobre fenômenos da linguagem presentes nesse passatempo, tais como sinonímia, onomasiologia e a distinção entre as palavras e as coisas. A continuação, serão avaliados quais dicionários seriam os mais apropriados para resolver problemas de palavras cruzadas.

Palavras-chave:Palavras cruzadas. Lexicografia. Onomasiologia.

\section{Cross-words puzzles as a language issue: solving it with the aid of the dictionary}

\begin{abstract}
Solving crosswords puzzles is a very common pastime. However, seldom linguists pay attention to the idiomatic issues crosswords puzzles reflect. This paper aims at discussing idiomatic issues in crosswords puzzles, like synonymy, onomasiology and the relationship between words and things. Further, we discuss what kind of dictionaries is suitable for solving crosswords puzzles.
\end{abstract}

Keywords: Crosswords. Lexicography. Onomasiology. 


\section{Introdução}

Entre os passatempos mais usuais, para muitas pessoas, as palavras cruzadas constituem, sem dúvida, um dos preferidos. Evidentemente, trata-se de um desafio múltiplo, já que testa desde a paciência, passando pelo que hoje a linguística aplicada chama de "competência léxica", até o raciocínio lógico.

O presente trabalho refletirá sobre o jogo das palavras cruzadas como problema da linguagem e sobre como o dicionário e até a internet podem ajudar na resolução desse tipo de passatempo.

\section{Palavras cruzadas: entre a linguagem e as coisas}

Já entre os gregos, existia uma preocupação muito grande em relação à linguagem, em questões tais como: se as palavras continham o "ser" das coisas que nomeavam", ou qual seria o seu significado "verdadeiro", que é a origem do que hoje conhecemos como etimologia, etc. Essas reflexões são o início de uma disciplina das ciências da linguagem, chamada de Filosofia da Linguagem. Essa área é uma reflexão sistemática referente a questões-chave sobre o mais complexo e perfeito sistema de comunicação que se conhece. Entre os problemas que preocupam a filosofia da linguagem (e também aqueles que se preocupam com dicionários), está a distinção (ou indistinção) entre o conhecimento referente às palavras, chamado de "competência linguística", e o conhecimento referente às coisas, chamado de "conhecimento enciclopédico". Dito em outros termos, sabemos, por exemplo, que existe certa correspondência entre as letras e os sons da língua portuguesa. Por esse princípio, sabemos que, na palavra haver, a primeira letra não se pronuncia. Por outro lado, é de conhecimento geral que Brasília é a capital do Brasil. Esses dois tipos de "saber" correspondem ao conhecimento das palavras e ao conhecimento das coisas, respectivamente. No entanto, os limites desses dois tipos de conhecimento não são claros. Por exemplo, uma frase tão comum como "A solução dada ao problema é uma solução feijão com arroz!" constitui um bom exemplo dos limites difusos entre o conhecimento das palavras e o conhecimento das coisas. Por um lado, a expressão feijão com arroz não é compreendida literalmente (palavra por palavra); pelo outro, sabemos que feijão e arroz constituem a base da alimentação do brasileiro. Por isso, hoje os estudiosos da linguagem acreditam que a separação entre os dois tipos de conhecimento não é possível. Na redação (e compreensão) das definições dos dicionários, essa questão é central.

\section{As palavras cruzadas como espelho da linguagem}

No âmbito do passatempo das palavras cruzadas, os problemas colocados para resolução obedecem, em parte, ao princípio exposto no parágrafo anterior. Há naturalmente, problemas que têm a ver exclusivamente com o conhecimento das palavras, tais como a procura por sinônimos. Eis alguns exemplos: prudente, moderada " "2 (Super Lazer, n. 209, p. 4), aborrecido, mal-humorado " " (Fácil Suave, n. 203, p. 3), gerar (filhos)! “" (Desafio cérebro, n. 291, p. 28), etc.

Muito mais interessantes são os problemas referentes às designações. Nesse quesito, o problema proposto nas palavras cruzadas é a inversão do verbete de um dicionário. Ao consultar um dicionário, o usuário recorre a uma listagem de palavras, geralmente disposta em progressão alfabética (na tradição de língua portuguesa, essa listagem é chamada de nominata). Ao aceder à palavra procurada, o consulente

1 Na linguística moderna, por exemplo, é famosa a frase "A palavra cão não morde" para denotar que não existe nenhuma motivação entre as palavras e as coisas.

2 Entre aspas estão representados os quadrinhos das palavras cruzadas que devem ser preenchidos com a resposta correta. 


\section{Extensio $\mid$ Dossier}

muda o sentido da busca, do plano vertical (descendente) para o plano horizontal (da esquerda para a direita). Exemplo: casa " 1 edifício de formatos e tamanhos variados, ger. de um ou dois andares, quase sempre destinado à habitação" (Hou (2009, s.v.)). No caso das designações, o redator de palavras cruzadas escreve "edifício de formatos e tamanhos variados, ger. de um ou dois andares, quase sempre destinado à habitação" (Hou (2009, s.v.)) e espera que a pessoa saiba que essa definição corresponde à designação casa. Eis dois exemplos: "Ausência total de realidade, no eleatismo" (designação) (Desafio cérebro, 291, p. 27), "Bulbo alimentar de sabor picante" (designação) (Ouro Euro, n. 12, p. 32). Diferentemente do que acontece com os sinônimos, para os quais existe um repertório de palavras para oferecer expressões análogas (o dicionário de sinônimos), dicionários em que primeiro apareça a definição e, depois, a designação que lhe corresponde são a absoluta exceção. Sterckenburg (2003, p. 134) menciona um caso para o inglês, e, na língua portuguesa, contamos com a obra de Rivellino (2001). É evidente o calcanhar de aquiles dessas obras, pois tentam, de fato, inverter a equação sêmica ${ }^{3}$. Se, nos dicionários "tradicionais" ${ }^{4}$ o princípio de ordenação é o alfabeto (que constitui um princípio de conhecimento geral para qualquer indivíduo alfabetizado), não existe, por outro lado, um princípio minimamente análogo quando se inverte a relação entre o lema e a definição. Como comentado mais acima, tentou-se dispor as informações dessa forma, conferindo-se a esse dicionário o nome de "dicionário reverso" [reverse dictionary], segundo Sterckenburg $(2003 \text {, ibid) })^{5}$. Os resultados são previsíveis. Não há um princípio de busca lógico. Essa classe de dicionários, pois, não possui quase nenhuma serventia. Ainda no campo das designações, há um tipo de problema de especial difícil resolução. Diferentemente dos casos anteriores, que correspondiam todos a substantivos, a busca de designações para os adjetivos é ainda mais complexa, como a comprovam os seguintes exemplos: Diz-se do tempo chuvoso (designação) (Desafio cérebro, n. 291, p. 24); Referente à boca e ao nariz (designação) (Super Lazer, n. 209, p. 11). Na terceira parte da exposição, voltaremos às particularidades que oferecem os adjetivos.

Uma competência linguística mais apurada exige, por exemplo, os problemas referentes a perguntas relativas a afixos (sufixo de goiaba “ "(Super Lazer, n. 209, p. 7), prefixo de antiético “ ” (Ouro Euro, n. 12, p. 22)), à morfologia (letra que indica o infinitivo verbal “ " (Desafio cérebro, n. 291, p. 39) interjeição de enfado “" (Ouro Euro, n. 12, p. 15)), à ortografia (vogal que levava o trema “ ” (Desafio cérebro, n. 291, p. 18)) e à fonologia (tipo de consoante“" (Ouro Euro, n. 12, p. 9)).

Nos parágrafos precedentes, fizemos referência a casos em que uma separação estrita entre as palavras e as coisas não é possível. Eis alguns exemplos: Ação do engraxate, em relação ao sapato " " (Fácil Suave, $\mathrm{n}$. 203, p. 21), Nível da psique reforçado pelo elogio “" (Desafio Cérebro, n. 291, p. 39), Mamífero típico da cordilheira andina " " (Desafio Cérebro, n. 291, p. 42), Baga doce e carnosa " ” (Ouro Euro, n. 12, p. 19).

A um âmbito muito diferente pertencem os problemas referentes às "coisas", ou seja, àquilo que está "fora da linguagem". A essa rubrica, bastante heterogênea, por sinal, correspondem tarefas tais como: Salvador (?), pintor “..." (Super Lazer, n. 209, p. 44), A arma de Zeus: (...) (Ouro Euro, n. 12, p. 27); representações

3 Chama-se "equação sêmica" a relação que se estabelece entre o lema (a palavra destacada em negrito) e o conjunto de informações referentes ao lema (BUGUEÑO MIRANDA, 2009).

4 A expressão "tradicional" se refere às obras mais comumente consultadas, ou seja, as obras ordenadas segundo o alfabeto.

5 Deve-se mencionar que o dicionário reverso não almeja, prioritariamente, satisfazer as demandas de quem resolve palavras cruzadas. No âmbito das obras lexicográficas, Rivellino (2001), pensado sim para essa tarefa, recebe o nome de "dicionário de palavras cruzadas". Contudo, essas obras se demonstram muito heterogêneas na sua constituição, de forma que o nome que recebem não significa que elas sejam expressamente desenhadas para essa função. Assim, tanto o caso do dicionário do inglês como Rivellino (2001) correspondem a uma situação nada infrequente na praxe lexicográfica: oferecer um mesmo dicionário com dois nomes diferentes. 
iconográficas, como uma em forma de charge de Napoleão Bonaparte e acrescida de um pequeno texto Conterrâneo de Fafá de Belém “ " (Fácil Suave, n. 203, p. 21) e Pianista que foi tema de documentário de João Moreira Salles “ ” (Desafio Cérebro, n. 291, p. 11). Ademais, há inúmeros casos de procura por equivalentes em língua estrangeira, basicamente em inglês e em francês: Negro em francês “ ” (Desafio Cérebro, n. 291, p. 18). A mais recorrente é o inglês, sem dúvida. Porém, não apenas o francês aparece com menos recorrência; há pedidos de equivalência também em relação ao espanhol.

\section{As palavras cruzadas e as estratégias para a sua resolução: 0 uso de dicionário}

No parágrafo anterior, ficou em evidência que as palavras cruzadas comportam várias classes de problemas linguísticos, e, o que é mais importante, a heurística para a sua resolução é diferente em cada caso.

Primeiramente, começaremos pelos problemas de cunho linguístico. Existem dois “sentidos" (em uma projeção espacial) para a relação que há em cada palavra de uma língua natural. Por um lado, uma palavra possui um conteúdo que, em alguns casos, corresponde a um conteúdo semântico. Em outros casos, corresponde a um conteúdo que se poderia chamar de "relacional" (cf. BUGUEÑO MIRANDA; FARIAS (2011) para essa discussão). Por outro lado, temos consciência das palavras por meio da sua materialização em um código sonoro e/ou escrito, ou seja, "sabemos" que as palavras possuem um significado e "sabemos" que as palavras possuem uma forma (sonora e/ou escrita). Do ponto de vista do passatempo das palavras cruzadas e em relação ao exposto no parágrafo inicial, se o problema proposto corresponde ao âmbito da sinonímia, é como se ele (por exemplo, atuar, proceder “ ” (Super Lazer, n. 209, p. 21)) e a sua solução (palavra de quatro letras: agir) correspondessem a um triângulo, no qual, nos ângulos inferiores esquerdo e direito, estivessem as representações sonoras e ortográficas atuar, proceder (lado esquerdo) e agir (lado direito). O extremo superior do triângulo corresponde ao conteúdo semântico comum para as três sequências sonoras e gráficas (atuar, proceder, agir): "exercer ação ou atividade".

Para esse tipo de tarefas, o dicionário de sinônimos é, sem dúvida, o mais apropriado. No mercado editorial brasileiro, há inúmeras obras desse teor. Citamos, como exemplo, Melhoramentos (1994), Michaelis (2009) e Houaiss (2011). Como uma particularidade dessa classe de dicionários, cabe salientar que a maioria das obras citadas, além de muitas outras, pertence ao que se chama de dicionários de "sinonímia cumulativa" (cf. BUGUEÑO MIRANDA (2008) para esse conceito), isto é, dicionários que simplesmente listam séries de sinônimos, sem estabelecer as diferenças sutis de significado que há, de fato, entre a maioria das palavras ditas sinônimas. Aparentemente e para efeitos de resolução de problemas de palavras cruzadas, a única condição da sinonímia está expressa pelo número de letras que o sinônimo deve possuir. No entanto, no parágrafo anterior, citamos o exemplo gerar (filhos), no qual o objeto direto filhos serve para indicar que a opção sinonímica correta é aquela que, semanticamente, exprime o conteúdo de procriar, e não de produzir, por exemplo, que também éum sinônimo de gerar. Para esses casos, HouSin (2011), que é o único dicionário que discrimina as nuances entre os sinônimos (e, por isso, classificável como dicionário de "sinônimos discriminantes"), é, sem dúvida, a melhor opção.

Uma situação mais complexa é a que apresenta aqueles problemas de palavras cruzadas nos quais é oferecida uma definição e se exige que se forneça a designação respectiva. Nesse ponto, se misturam três problemas complementares entre si. Em primeiro lugar, a própria tarefa proposta. Em segundo lugar, que estratégias empregar para resolver a tarefa. Em terceiro lugar, a compreensão da informação fornecida.

No que diz respeito à tarefa proposta, ela se inscreve na perspectiva onomasiológica, como já mencionado. Aliás, na nossa própria atividade linguística cotidiana, nos confrontamos com a perspectiva onomasiológica, quando, por exemplo, queremos dizer ou escrever algo, mas não lembramos da "palavra" (na verdade, não lembramos de como se diz ou se escreve).

Em relação aos mecanismos estratégicos para resolver a tarefa, o exemplo dado com o verbete casa demonstrou

6 Maior líder político e militar da história da França, foi derrotado em 1815, na batalha de Waterloo " " (Desafio Cérebro, n. 291, p. 3). 


\section{Extensio $\mid$ Dossier}

que os dicionários inversos são (ainda) inviáveis. No entanto, existem outros dicionários para satisfazer as demandas onomasiológicas. Entre eles, há o dicionário analógico de natureza onomasiológica. Nessa classe de dicionários, são oferecidas as designações para a nominata estabelecida para o dicionário. É preciso salientar, contudo, que esses dicionários possuem pelo menos três restrições para quem deseje utilizá-los para resolver problemas de palavras cruzadas. Por um lado, com o intuito de tornar viável a organização das informações do ponto de vista do conteúdo, é necessário dispô-lo em uma ontologia, que é uma interpretação do léxico de uma língua de acordo com um determinado ponto de vista. Até agora, não se conta com uma ontologia de valor e aceitação universal, de maneira que cada dicionário onomasiológico acaba por elaborar uma própria ${ }^{7}$. Dada a sua compreensível complexidade, o redator de um dicionário onomasiológico precisa apresentar um "plano" da ontologia que gerou, para que o consulente consiga compreender como deve procurar. Na prática, isso significa que o consulente deve "aprender" como pesquisar novamente cada vez que consulta um outro dicionário onomasiológico. Por outro lado, a codificação da informação contida no dicionário onomasiológico não corresponde completamente à tarefa apresentada nas palavras cruzadas, isto é, nos dicionários onomasiológicos, tampouco há definições para as quais se ofereça, a posteriori, uma designação. Finalmente, a última restrição tem a ver com o fato de os falantes de língua portuguesa contarem com pouquíssimos dicionários onomasiológicos. O mais conhecido seja, talvez, Sargentim (s/d). Contudo, essa obra está estruturada da mesma forma que os demais dicionários onomasiológicos.

Das considerações precedentes, poder-se-ia concluir que os dicionários onomasiológicos não possuem nenhuma serventia imediata para a resolução de palavras cruzadas. É pertinente destacar também que o problema maior não está em se, per se, essa classe de dicionários pode ou não cumprir essa tarefa. Na verdade, sim, pode. Para compreender melhor a questão, faz-se necessário reconhecer que há um desencontro entre a forma como o problema é apresentado para quem resolve palavras cruzadas e a forma como os dicionários onomasiológicos ordenam as informações para que elas possam ser procuradas pelo consulente. Em comum, tanto quem resolve palavras cruzadas como quem compila um dicionário estão perante uma perspectiva onomasiológica da linguagem (do conteúdo à expressão). O que os diferencia é que, no caso das palavras cruzadas, o input informacional é uma definição, enquanto que, no caso do dicionário onomasiológico, é uma ontologia, normalmente representada através de entidades nominais hiperonímicas. Lembramos também que a onomasiologia já tentou, sem sucesso, empregar definições para aceder às informações no dicionário. Nessas condições, está-se perante um problema que os metalexicógrafos (os teóricos da lexicografia) chamam de estrutura de acesso, ou seja, o princípio formal que possibilita ao consulente de um dicionário procurar e encontrar a informação requerida (cf. HARTMANN, JAMES (2001, s.v. access structure)).

Embora não fora cogitado ex professo para a resolução de problemas de palavras cruzadas, o Dicionário Mais (1997), doravante citado como DM (1997), tentou resolver a questão da estrutura de acesso dos dicionários onomasiológicos e se torna, assim, um instrumento útil de consulta para esse passatempo.

É evidente que as ontologias dificultam sensivelmente a busca de informação. Por isso, o DM (1997) optou por uma estrutura de acesso alfabética, mas somente para facilitar a busca do consulente ${ }^{8}$. No interior de cada verbete, o dicionário emprega a solução do dicionário inverso. Transcreve-se a continuação o verbete predição:

7 Note-se que, em comparação ao dicionário onomasiológico, o dicionário semasiológico, sempre ordenado segundo a progressão alfabética, é extremamente simples.

8 Na verdade, essa solução é a empregada pela lexicografia francesa (à qual pertence também DM (1997)) com o intuito de facilitar o manuseio do dicionário ao consulente. Contudo, DM (1997) oferece também outras valiosas soluções, como se verá na exposição, que o tornam único 


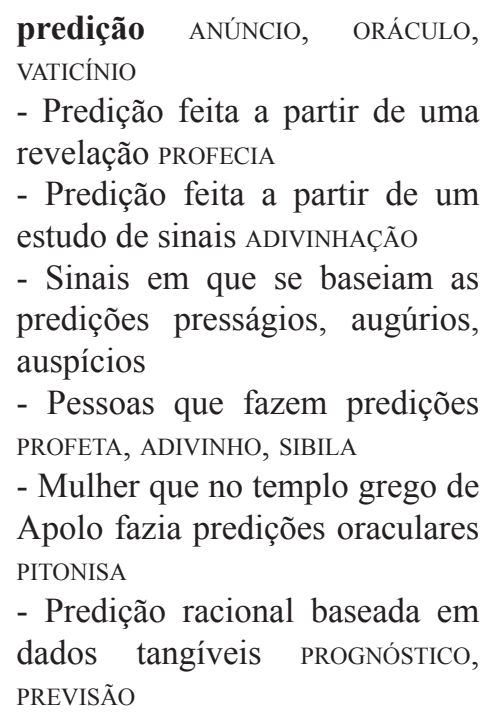

DM (1997, s.v.)

Após o lema (a palavra em negrito), aparecem três palavras em versalete (anúncio, oráculo, vaticínio). O versalete indica que o consulente pode procurar nesses verbetes também. Depois, seguem as definições e, à sua direita, as designações correspondentes. Note-se que o lema predição constitui um hiperônimo em relação aos hipônimos profecia, adivinhação, etc. O desafio central para quem resolve palavras cruzadas é saber sob que lema procurar a relação significado-designação. Voltaremos ao assunto nos parágrafos seguintes.

O DM (1997) oferece também muitos outros tipos de informações úteis. Entre os problemas de palavras cruzadas, mencionamos os casos Diz-se do tempo chuvoso (designação) (Desafio cérebro, n. 291, p. 24) e Referente à boca e ao nariz (designação) (Super Lazer, n. 209, p. 11). Do ponto de vista da linguística, a redação das definições, particularmente as palavras que iniciam a frase (Diz-se de, Referente a) são evidências completas de que se está perante uma categoria sui generis de adjetivos, chamados de adjetivos relacionais (cf. DEMONTE (1999) para esse conceito). Portanto, a primeira pista para resolver o problema está dada pelo próprio modelo de redação da definição, pois os adjetivos relacionais se destacam justamente por apresentar, na sua definição, sempre o mesmo tipo de modelo de redação. Naturalmente, volta-se à questão central da formulação de problemas de busca de designações nas palavras cruzadas. O DM (1997, s.v. forma) oferece um quadro contendo os adjetivos que derivam de entidades nominais e que obedecem ao padrão semântico dos adjetivos relacionais. Eis alguns exemplos:

EM FORMA DE

\begin{tabular}{|ll|l|}
\hline agulha & $\begin{array}{l}\text { acicular } \\
\text { aciculado }\end{array}$ & filiforme \\
\hline ampola & buliforme & gapcho unciforme \\
\hline arco & arciforme & hellice helicoidal \\
\hline asa & aliforme & lamela lameliforme \\
\hline
\end{tabular}

\section{DM (1997, s.v.)}

Função análoga cumprem quadros referentes aos nomes da pelagem do cavalo (DM (1997, s.v. cavalo), os nomes aplicados às pessoas segundo o que colecionam ("colecionador de bandeiras" = vexilofilista, por exemplo) (DM (1997, s.v. colecionador) e dos habitantes das diferentes comarcas de Portugal (DM (1997, s.v. habitante).

Além disso, o DM (1997) demonstra claramente aquilo que foi dito referente à dificuldade de se estabelecer um limite claro, em muitos casos, entre as palavras e as coisas, ou entre a informação linguística e 


\section{Extensio $\mid$ Dossier}

a enciclopédica. O dicionário apresenta uma riquíssima variedade de informações que podem ser chamadas de fatuais, tais como as correntes do pensamento filosófico (DM (1997, s.v. filosofia)), os medicamentos (DM (1997, s.v. medicamento) e as principais moedas estrangeiras (DM (1997, s.v. moeda)).

Por último, fazendo jus à sua condição onomasiológica, há inúmeras gravuras apresentando, através da imagem, muitos campos léxicos, tais como um diagrama em corte vertical da Catedral de Paris, com ênfase nas particularidades arquitetônicas (DM (1997, s.v. catedral)), os principais músculos do corpo (DM (1997, s.v. músculo)) e as classes de queijos (DM (1997, s.v. queijo)).

\section{Os saberes nas palavras cruzadas}

A exposição dos parágrafos anteriores deixa em evidência que o passatempo das palavras cruzadas privilegia, por igual, o conhecimento das palavras e das coisas. Em relação à diferenciação estrita entre esses dois saberes, já foi comentado que uma linha divisória clara, em muitos casos, não é possível. Em seguida, procuraremos demonstrar como a própria formulação dos problemas de palavras cruzadas espelha essa situação. Primeiramente, serão fornecidos exemplos em que o conhecimento das palavras e as coisas se confundem: Tipo de explosivo que possui coloração amarela (Super Lazer, n. 209, p. 13); Dois tipos de combustíveis (Super Lazer, n. 209, p. 14); Canal de áudio da televisão (Super Lazer, n. 209, p. 14); O dia em que preguiçoso faz as coisas (Desafio Cérebro, n. 291, p. 32); Espécie como o lêmure (Desafio Cérebro, n. 291, p. 37) e Órgão que também pode ser objeto de doação (Ouro Euro, n. 12, p. 13). Em todos esses casos, a resolução do problema não tem a ver diretamente com a linguagem per se, mas sim com o conhecimento das "coisas". A fronteira sutil entre o conhecimento das palavras e das coisas é especialmente perceptível no caso de Dois tipos de combustível. Em BUGUEÑO MIRANDA; FARIAS (2012), faz-se uma análise dessas e de outras definições (paráfrases explanatórias) e conclui-se que nessa, como em muitas outras definições, há um baixo poder extensional na paráfrase proposta, ou seja, as informações linguísticas (as palavras) são pobres para reconhecer a "coisa" na realidade.

Em outros casos, é perfeitamente possível reconhecer a "coisa na realidade", como em Móvel sobre o qual se come, escreve e trabalha (= mesa) (Super Lazer, n. 209, p. 15); Prato da culinária brasileira preparado com feijão (= feijoada) (Super Lazer n. 209, p. 22); Carnívoros que tiram presas do leão (= hienas) (Ouro Euro, n. 12, p. 15). Particularmente, nos casos de Prato da culinária brasileira preparado com feijão e Carnívoros que tiram presas do leão, é o conhecimento das coisas, muito mais do que da linguagem, que permite identificar de que palavra se trata.

Nos dicionários, esses problemas se repetem. Brangel (2011), por exemplo, demonstrou que o tratamento das cores nos dicionários monolíngues é extremamente difícil, já que a evocação ao mundo das coisas é tão essencial que a própria formulação linguística não consegue "explicar" o que uma cor determinada significa. Por isso, Brangel (2011) conclui que a melhor forma de tratar dessas entidades da linguagem é por meio da "substituição ostensiva”, ou seja, do emprego de um outro sistema semiótico (gravuras). Em relação a outras palavras, citam-se dois exemplos extraídos de Au (1999): contra-ataque "S.m. (...) 2. Mil. Ação ofensiva temporária e local, desencadeada por uma força encarregada da defesa de uma posição [Pode ter por fim restabelecer uma posição defensiva (reconquistando o terreno cedido ao inimigo), desorganizar a força atacante, ou cortar-lhe as vias de retirada]" (s.v.) e filame "S.m. Marinh. A porção de amarra compreendida entre a abita, ou onde esteja com volta passada, e o anete da âncora" (s.v.). Particularmente no caso de contra-ataque, o redator do verbete viu-se diante da necessidade de acrescentar um pós-comentário semântico (cf. FARIAS (2011) para esse conceito), para tentar incrementar a capacidade de compreender o que contra-ataque significa. 


\section{Conclusões}

O passatempo das palavras cruzadas deixa em evidência vários problemas que afetam, além dos aficionados, especialistas em semântica, lexicografia e filosofia da linguagem. No que diz respeito aos estudiosos da semântica, velhas distinções, como intensão e extensão, conhecimento das palavras e conhecimento das coisas, palavras com conteúdo e palavras sem conteúdo, etc., começam a ser postas em dúvida perante as evidências que a pesquisa na área aporta. Para os teóricos e redatores de dicionários, um dicionário onomasiológico continua a ser um desideratum que requer a máxima atenção. Em relação aos filósofos da linguagem, a natureza da linguagem, com essa aporia entre a exatidão e a vagueza que o mais complexo dos sistemas semióticos apresenta, leva de volta sempre a essa frase de Herder: "Já na sua condição animal, o homem fala" [Schon als Thier, hat der Mensch Sprache]. Finalmente, para resolver palavras cruzadas, o usuário deve estar ciente de que a resolução desse passatempo não é uma atividade trivial, mas sim um exemplo da complexidade da linguagem.

\section{Referências}

BRANGEL, L. Definições de cores em um dicionário semasiológico com o auxílio da semântica cognitiva. Porto Alegre, 190 f. Dissertação de Mestrado em Linguística (Programa de Pós-Graduação em Letras) - Universidade Federal do Rio Grande do Sul, 2011.

BUGUEÑO MIRANDA, F. Para uma taxonomia de paráfrases explanatórias. .Alfa, São José do Rio Preto, v. 53, 2009 p. 243-260.

. Panorama da lexicografia alemã. Contingentia, Porto Alegre, v. 3, 2008, p. $89-110$.

; FARIAS, V. . Los subsidios de tres teorías semánticas para la generación de definiciones lexicográficas. Revista de Filología de la Universidad de la Laguna, La Laguna, v 30 [no prelo], 2012.

Sobre las palabras y su clasificación según su contenido. Los problemas del lexicógrafo. Revista de Filología de la Universidad de la Laguna, La Laguna, v. 29, 2011, p. 9-19.

DEMONTE, V. El adjetivo. Clases y usos. La posición del adjetivo en el sintagma nominal. In: BOSQUE, I.; DEMONTE, V. (org.). Gramática descriptiva de la lengua española, Madrid: Espasa Calpe, RAE, Colección Nebrija y Bello, 1999, v. 1, 5504p.

DESAFIO CÉREBRO. Rio de Janeiro: Ediouro publicações de passatempos e multimídia, n. 291.

FARIAS, V. Considerações preliminares sobre o pós-comentário na microestrutura de dicionários semasiológicos. Revista Virtual de Estudos da Linguagem. Porto Alegre v. 9, 2011 p. 109-139.

HARTMANN, R.R.K.; JAMES, G. Dictionary of lexicography. London: Routledge, 2001. 
INSTITUTO ANTÔNIO HOUAISS (Ed.). Dicionário Houaiss de sinônimos e antônimos. São Paulo: Publifolha, 2011.

LISBOA EDITORA. Dicionário mais: da idéia às palavras. Lisboa: Lisboa Editora, 1997.

MELHORAMENTOS (Ed.). Minidicionário Melhoramentos de sinônimos e antônimos. São Paulo: Melhoramentos, 1994.

MICHAELIS (Ed.). Dicionário Michaelis de sinônimos e antônimos. São Paulo: Michaelis, 2009.

FÁCIL SUAVE. Rio de Janeiro: Ediouro publicações de passatempos e multimídia, n.203.

OURO EURO. Rio de Janeiro: Ediouro publicações de passatempos e multimídia, n.12.

RIVELLINO, M. Dicionário de palavras cruzadas e charadismo. Belo Horizonte: Garnier, 2001.

SARGENTIM, H. Dicionário de idéias afins. São Paulo: IBEP, s/d.

STERCKENBURG, P. V. Onomasiological specifications and a conccise history of onomasiological dictionaries. In: STERCKENBURG, P. V. A practical guide to lexicography. Amsterdam: John Benjamins, 2003, p. 127-143.

SUPER LAZER. Salto: G.G. Guarda Editora e Distribuidora ME, n, 209. 